\section{Mechanical Hedge Pruning of Pecan in a Relatively Low-light Environment}

\author{
Bruce W. Wood ${ }^{1}$ \\ U.S. Department of Agriculture, Agricultural Research Service, Southeastern \\ Fruit and Tree Nut Research Laboratory, 21 Dunbar Road, Byron, GA \\ 31008-0087
}

Additional index words. alternate bearing, flowering, hedging, irregular bearing, mechanization, profit, production, pruning, quality, yield

\begin{abstract}
Long-term productivity of commercial pecan [Carya illinoinensis (Wangenh.) $K$. Koch] enterprises in relatively low-light environments such as the southeastern United States are limited by excessive tree crowding as orchards age. An effective horticultural strategy for countering this problem in relatively high-light environments is mechanical hedge-type pruning; however, uncertainty persists regarding the best strategies in lowlight environments. This report describes the results of a 4-year study regarding the response of $\approx 25$-year-old 'Desirable' pecan trees to different mechanical hedgerow-type, moderate canopy width (i.e., 2.43-m cuts from tree axis) pruning strategies. Canopy treatments were nonpruned control (NPC), annual dormant season side-hedge pruning on two faces, annual summer season side-hedge pruning on two faces, and alternating annual dormant season side-hedge pruning on a single alternating face. Relative to the NPC treatment, all three pruning strategies: 1) reduced in-shell nut yields by roughly $19 \%$ to $38 \% ; 2$ ) reduced marketable nut-meat yield by $\approx 19 \%$ to $36 \% ; 3$ ) failed to stimulate shoot development or fruiting within the central interior zone of tree canopies; 4) increased kernel percentage of nuts; 5) increased nut-meat grade; 6) substantially reduced alternate bearing intensity $(I=0.51$ to $\approx 0.20)$; and 7$)$ reduced orchard crowding. Pruning-associated reductions in nut yield appear sufficient to limit the commercial usefulness of annual or biennial mechanical hedgerow-type pruning of 'Desirable' pecan orchards at moderate canopy widths in relatively low-light environments such as the southeastern United States.
\end{abstract}

The profitability of pecan [Carya illinoinensis (Wangenh.) K. Koch] orchard enterprises eventually decline if tree canopies encroach to cause excessive orchard shading. This deterioration of canopy light environment, and associated "sunlight stress", typically increases alternate bearing intensity ( $I$; Pearce and Dobersek-Urbanc, 1967), which is perhaps the economically most important biological problem faced by commercial pecan enterprises. Timely use of mechanized hedge-type pruning as a horticultural tool is potentially an effective approach for preventing orchard crowding and partial moderation of alternate bearing (Wood and Stahmann, 2004). It is increasingly adopted by commercial enterprises at high-light geographic locations; however, its usefulness at relatively low-light locations such as those of the southeastern United States merits assessment.

The relatively low-light environment of the southeastern United States exhibits considerable cloud cover and atmospheric water vapor (i.e., relative humidity) throughout the growing season. An important cultivar grown

Received for publication 9 Oct. 2008. Accepted for publication 6 Nov. 2008.

The cost of publishing this paper was defrayed in part by the payment of page charges. Under postal regulations, this paper therefore must be hereby marked advertisement solely to indicate this fact.

${ }^{1}$ To whom reprint requests should be addressed; e-mail bruce.wood@ars.usda.gov. orchard, in a low-light environment, to three different short-cycle, moderate-width mechanical side-hedge pruning strategies. It is concluded that moderate-width mechanized side-hedge pruning of 'Desirable' does little to increase fruiting within the inner canopy and that short hedge-type cycles likely possess little commercial potential as a viable horticultural canopy management tool for 'Desirable' orchards located in relatively low-light environments.

\section{Materials and Methods}

Orchard site characteristics. The study orchard is located within a Subtropical Climatic Group zone at Byron, GA (lat. $32^{\circ} 39^{\prime} 54^{\prime \prime} \mathrm{N}$, long. $83^{\circ} 44^{\prime} 31^{\prime \prime} \mathrm{W}$ ). The test orchard is at an elevation of $\approx 155 \mathrm{~m}(509 \mathrm{ft})$ growing on a Faceville fine sandy loam soil (FoA; fine, kaolintic, thermic Typic Kandiudult) and at a tree spacing of $9.1 \mathrm{~m} \times 18.2 \mathrm{~m}$ $(30 \times 60 \mathrm{ft})$. The site has a freeze-free growing period of $\approx 240 \mathrm{~d}$ with annual precipitation of $\approx 1.81 \mathrm{~m}$ (46 inches). The relatively low-light orchard site is typical of the southeastern U.S. pecan belt in that it receives $\approx 60 \%$ to $70 \%$ of "possible" (i.e., of the theoretical maximum; deviations from this maximum is as a result of clouds, humidity, dust, aerosols, and particulates) sunlight during the growing season as compared with $\approx 80 \%$ to $90 \%$ in a high-light environment such as the southwestern United States and has mean annual relative humidity of $\approx 70 \%$ (Jacobs, 1968).

Orchard management characteristics. The study orchard is comprised of 'Desirable' trees whip-grafted to open-pollinated 'Elliott' rootstocks. Trees were established as bare-root transplants in 1984. Orchard trees were initially spaced at $9.1 \mathrm{~m} \times 9.1 \mathrm{~m}$, but thinned in 1998 to a $9.1 \mathrm{~m} \times 18.2-\mathrm{m}$ spacing with rows running north-south. Subsurface drip irrigation lines, with drip emitters rising to the soil surface at 1-m intervals, supplemented tree water needs. Parallel irrigation lines run the length of tree rows positioned $\approx 1.2 \mathrm{~m}$ on either side of tree trunks. Drip emitters delivered water at $3.78 \mathrm{~L}$ per hour for $\approx 8$ to $12 \mathrm{~h}$ per day, depending on water needs, throughout the growing season. Irrigation lines are within a herbicide strip maintained in a bare state using glyphosate (Monsanto, St. Louis, MO). Trees received annual broadcast applications of nitrogen, potassium, phosphorous, magnesium, and calcium as needed, based on previous July leaf analysis, at principal leaf development growth stage "11" (Finn et al., 2007). Canopies also receive foliar sprays of zincsulfate, as needed, during canopy expansion (growth stage 11 to 17 ) each spring. Orchard management includes routine foliar sprays of pesticides to control pecan scab disease and various arthropod pests as prescribed by the Georgia Extension Service recommendations for commercial orchards (Hudson et al., 2007). Pest management practices produced nuts with little or no pecan scab damage and 
little or no fruit drop or fruit damage by arthropod pests.

Experimental design. The experiment tests whether moderate-width, side-hedgetype mechanical pruning of canopies mitigates orchard crowding problems in 'Desirable' pecan orchards located in a subtropical climate group zone (Trewartha, 1968) possessing relatively low-light conditions during the growing season while avoiding a negative impact on marketable nut meat yield. The experiment is comprised of three moderatewidth canopy mechanical side-hedge-type pruning treatments plus a nonpruned control (Fig. 1). Pruning cuts are relatively shortcycle with cuts made on an annual or biennial basis depending on treatment. Hedge-type pruning cuts, $2.43 \mathrm{~m}$ [ 8 feet or canopy width at $4.86 \mathrm{~m}$ (16 feet)] from the central axis of trunk, were made during January to February beginning in 2003 and ending in 2006, thus spanning four production seasons or two alternate bearing cycles. Treatments are: 1) nonpruned control (NPC); 2) east and west faces of the canopy hedge pruned annually during dormant season (HD); 3) east and west faces of the canopy pruned during dormant season, but with only one face pruned annually on a 2-year cycle (HD2; for the initial pruning cut, this treatment was pruned in the dormant season and again in early summer; however, subsequent cuts were made in early summer); and 4) east and west faces of canopy pruned annually in late June (HS) after complete expansion of the foliar canopy. Experimental design consisted of four mechanical hedging treatments structured as a randomized complete block consisting of four blocks $(\mathrm{n}=16)$. Experimental units were comprised of four to seven trees. Hedged treatments were established in three-row treatment plots comprised of $\approx 27$ trees with data taken from the center row, whereas the east and west outside rows served as buffers. Treatment effects were analyzed for each "year" using analysis of variance (ANOVA) for treatment effects and Tukey-Kramer honestly significant difference (HDS) tests for mean separation. The alpha level used to judge significance was $\leq 0.05$ for all statistical tests.

The various pruning treatments were assessed, at the conclusion of the 4-year study for flowering, shoot development, and photosynthetic photon flux density (PPFD) within the interior of the tree canopy. Canopy interiors were measured for these parameters at each of three locations along the central axis of the tree at one-fourth, one-half, and three-fourths elevations within the canopy. The measurement zone was a $1.8 \mathrm{~m}(6 \mathrm{ft})$ diameter spherical zone at each of the three sampling locations. Values were averaged to reflect the status of these parameters within the interior of the canopy. PPFD was measured using a Li-191 Line Quantum Sensor (LI-COR, Lincoln, NE) with readings taken between 1400 and $1500 \mathrm{HR}$ solar time to assess penetration of light through side canopies to the interior of the tree canopy. Data analysis was by ANOVA with mean separation by Tukey-Kramer HSD tests.

Mechanical pruning was by a hedging machine equipped with a $6.6-\mathrm{m}$ (20 feet) saw bar comprised of five $1.3-\mathrm{m}$ ( 4 feet) saw blades capable of reaching a height of $16.8 \mathrm{~m}$ (55 feet). Pruning cuts to canopies were made at a near vertical angle but with a

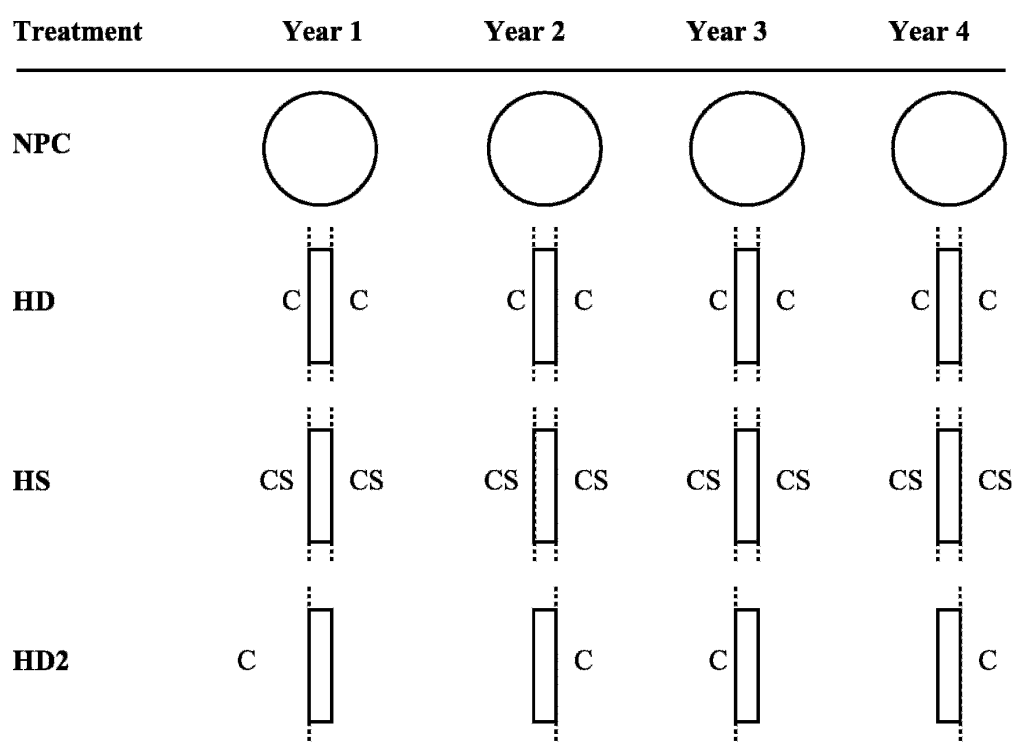

Fig. 1. Schematic (not to scale) of mechanical hedging-type pruning cuts to 'Desirable' canopies. Hedging cuts were made $2.43 \mathrm{~m}$ ( 8 feet) from the trunk beginning in 2003 and ending in 2006, thus spanning four production seasons. Treatments are: 1) nonpruned control (NPC); 2) east and west faces of the canopy hedge-pruned annually during dormant season (January-February) (HD); 3) east and west faces of canopy pruned annually early summer (HS; late June); and 4) east and west faces of the canopy pruned during dormant (January-February) season, but with only one face pruned annually on a 2-year cycle [HD2; for the initial pruning cut, this treatment was pruned in the dormant (January-February) season and again in late June; however, subsequent cuts were made in early summer (late June)]. "C" = cut during the dormant season; "CS" = cut during late June. $5^{\circ}$ tilt toward the canopy apex. Trees were not topped at any time during the study period. Trees within rows were cut (i.e., pruned) on two faces (i.e., east and west facing canopies) with the opposite faces (i.e., north and south faces) being allowed to encroach with the ultimate goal being to produce a hedgerow or continuous canopy configuration. During the timespan of this study, orchard-row canopies were discrete and had not yet merged into true hedgerows. Although treatment plots were not absolutely uniform regarding offvarieties and missing trees, the associated variation was essentially homogeneous across the study orchard and treatments. The occasional off-cultivar was 'Sumner'-relatively late ripening compared with 'Desirable', thus enabling harvesting of 'Desirable' plots without significant crosscontamination with 'Sumner' nuts.

Harvesting was by a hydraulic tree shaker and a mechanized sweeper and harvester with loads of nuts weighed after collection from each experimental unit. Subsamples were taken from the bulked harvest of each experimental unit, percent trash determined, and plot weights adjusted to estimate clean inshell nuts. These nuts were then shelled to determine nut meat percentage, i.e., percentage kernel. Kernels were then screened to discard nonmarketable meats (i.e., amber color, fuzz, defects, adhering materials, shriveled meats, and so on), thus enabling determination of marketable nut meats produced by each treatment [i.e., (in-shell nuts) $\times(\%$ kernel $) \times(\%$ fancy + choice $)=$ marketable nut meats]. The yield values of the 'Desirable' trees within the middle row of each plot were mathematically expanded before statistical analysis to equate to 1 ha of orchard trees. This was done to equate treatment effects to real-world yields reflective of commercial operations producing 'Desirable' nuts. Alternate bearing indices were calculated for both in-shell and marketable yields according to the method of Pearce and Dobersek-Urbanc (1967).

\section{Results and Discussion}

In-shell yield and alternate bearing. The crowded 'Desirable' orchard was entering a heavy crop year (ON year) when initial pruning cuts were made to canopies in 2003 . The removal of productive canopy by all of the three pruning treatments substantially reduced in-shell nut yield during the first production season (Table 1). In-shell yields produced by the NPC, or control, treatment were substantial for 'Desirable' at 1892 $\mathrm{kg} \cdot \mathrm{ha}^{-1}$. First-year yield reduction was greatest in the HD and HS treatments $(65 \%$ and $59 \%$ of the control, respectively), with the HD2 treatment being $\approx 78 \%$ of the NPC control. Although the HD and HS treatments removed a substantial portion of the tree canopy, in-shell yield was not reduced in direct proportion to canopy loss. Additionally, the removal by summer pruning of the regenerated vegetative canopy did not reduce first-year in-shell yield relative to that of the 
Table 1. Annual in-shell nut yield and associated alternate bearing index (ABI) for 'Desirable' trees receiving one of four mechanical pruning treatment strategies in each of 4 years beginning in 2003 . $^{2}$

\begin{tabular}{|c|c|c|c|c|c|c|}
\hline \multirow[b]{2}{*}{ Pruning treatment } & \multicolumn{5}{|c|}{$\begin{array}{l}\text { Annual in-shell nut yield } \\
\qquad\left(\mathrm{kg} \cdot \mathrm{ha}^{-1}\right)\end{array}$} & \multirow{2}{*}{$\begin{array}{l}\text { ABI of in-shell nuts } \\
(I)\end{array}$} \\
\hline & 2003 & 2004 & 2005 & 2006 & Avg & \\
\hline Nonpruned control (NPC) & $1,892 \mathrm{a}^{\mathrm{y}}$ & $747 \mathrm{a}$ & $2,594 \mathrm{a}$ & $231 \mathrm{~b}$ & $1,366 \mathrm{a}$ & $0.61 \mathrm{a}$ \\
\hline $\begin{array}{l}\text { Annual winter } \\
\text { cuts to two faces (HD) }\end{array}$ & $1,224 \mathrm{c}$ & $576 \mathrm{a}$ & $1,083 \mathrm{~b}$ & $918 \mathrm{a}$ & $950 \mathrm{~b}$ & $0.25 \mathrm{~b}$ \\
\hline $\begin{array}{l}\text { Annual summer } \\
\text { cuts to two faces (HS) }\end{array}$ & $1,116 \mathrm{c}$ & $642 \mathrm{a}$ & $832 \mathrm{~b}$ & $525 \mathrm{ab}$ & $779 \mathrm{~b}$ & $0.21 \mathrm{~b}$ \\
\hline $\begin{array}{l}\text { Biennial winter } \\
\text { cuts to alternate } \\
\text { faces (HD2) }\end{array}$ & $1,484 \mathrm{~b}$ & $822 \mathrm{a}$ & $1,008 \mathrm{~b}$ & $771 \mathrm{ab}$ & $1,021 \mathrm{~b}$ & $0.18 \mathrm{~b}$ \\
\hline
\end{tabular}

${ }^{\mathrm{z}}$ Nonpruned control (NPC); annual pruning on two faces in winter (HD); annual pruning on two faces in summer (HS); and biennial pruning on alternate faces in winter (HD2).

${ }^{\mathrm{y}}$ Means within columns followed by different letters are significantly different at $\alpha \leq 0.05$ level by TukeyKramer honestly significant difference test.

less invasive HD treatment. This result contrasts with that observed by Lombardini (2006) in which less severely hedge-pruned, or hand-pruned, 'Desirable' trees did not exhibit a first-year reduction of in-shell nut yield. The difference is partially attributable to difference in severity of pruning cuts between the two studies and to the presence of irrigation.

There was poor return fruit set the subsequent crop year (OFF year) (Table 1). The NPC treatment exhibited the typical alternate bearing-associated drop in cropload following the previous ON year. In-shell nut yield in the OFF year of the NPC treatment was only $39 \%$ that of the previous ON year. All three pruning treatments (i.e., HD, HS, and HD2) also produced a small return crop in 2004 with in-shell yields $\approx 47 \%$ to $57 \%$ of their previous season yields. Thus, the degree of cropload reduction exhibited by the HD, HS, and HD2 pruning treatments in 2003 was insufficient to ensure a crop increase in the subsequent 2004 crop season. There was no in-shell yield difference in 2004 among the four treatments; hence, effects of mechanized canopy pruning were not statistically apparent during the subsequent crop year when assessed based on in-shell nut yields.

The third crop year (2005) was an ON year, with NPC trees exhibiting a heavy crop at $2594 \mathrm{~kg} \cdot \mathrm{ha}^{-1}$ of in-shell nuts (Table 1). Inshell yields in all three pruning treatments were greater in this third year after pruning than in the previous OFF year. In-shell nut yields in 2005 were less for pruned trees than for nonpruned control trees, being $\approx 32 \%$ to $42 \%$ of the yield produced by the NPC treatment. There was no in-shell yield difference among the three hedge-pruned treatments.

The fourth crop year (2006) was an OFF year with in-shell yield declining for all four treatments relative to the previous season's yield (Table 1). The NPC treatment was relatively light with only $231 \mathrm{~kg} \cdot \mathrm{ha}^{-1}$. The HD pruning treatment resulted in an in-shell yield that was approximately fourfold greater than that of the NPC treatment; yet, it was not statistically greater than that of the other two pruning treatments. Although there is a strong trend for an absolute difference in in- shell yield between the NPC and the NS and ND2 treatments, the difference is not statistically significant but might have been so with greater replication. It is clear that by the fourth year of hedge pruning, both the HD and HD2 treatments looked promising.

An evaluation of 4-year average in-shell yields indicates that pruning by the three strategies evaluated in this study reduces inshell yield relative to the NPC control of crowding trees (Table 1). This reduced inshell yield by the three hedge pruning treatments is such that nut production is $\approx 57 \%$ to $75 \%$ of the NPC control. Although mechanical pruning reduced in-shell yields, all three strategies reduced the magnitude of alternate bearing ( $I=0.18$ to 0.25$)$ relative to that of the NPC control $(I=0.61)$. At an $I$ of 0.61 , 'Desirable' trees exhibited moderate alternate bearing, with the cause likely the result of competition for light linked to excessive tree encroachment and associated orchard crowding. Observations on biennial cycling, before the initiation of this study when trees were far less crowded, indicate that year-toyear yield fluctuations were considerably less than that observed on tree crowding. The alternate bearing index of the NPC trees in the present study was higher than that reported for nonpruned 'Desirable' trees growing in Texas (i.e., $I=0.22$; Lombardini, 2006). The high alternate bearing index exhibited by the present study is likely the result of a combination of substantially higher ON year in-shell yields and excessive canopy crowding. The alternate bearing index for 'Desirable' was previously estimated by Conner and Worley (2000) to be $\approx 0.36$ to 0.40 for nonhedge-pruned trees in noncrowded orchards depending on tree age and disease management. Alternatively, Worley (1985) observed that a form of hedge pruning yielded an $I$ of 0.40 over an 8-year period, which was equivalent to the nonpruned control treatment (i.e., $I=0.40$ ). Thus, in the present study, side-hedging canopies at moderate widths reduced alternate bearing intensity to that observed by Worley (1985) for 'Desirable' (i.e., 0.18 to 0.25 versus 0.40 ). The difference in magnitude of $I$ is likely to be at least partially because nonpruned trees in the present study were substantially crowded and therefore stressed. The $I$ values for hedge-pruned trees in the present study ( $I=$ 0.18 to 0.25$)$ are about equal to those $(I=$ 0.21 ) reported by Wood and Stahmann (2004) for 2-year cycle hedge-pruned 'Desirable' trees in Australia.

Nut meat quality. Nut quality is also an important yield component. The percentage of kernel within nuts as well as that of kernel color and presence of flaws that reduce marketability is key to maximizing orchard profits. Kernel percentage in 2003 was substantially improved because of the HD and HS hedging treatments during the first production year, yielding an approximate absolute increase in percentage kernel of $4 \%$ (or "four points"; Table 2). This increase can have a great impact on economic returns and profitability. Similarly, all three pruning strategies produced a higher percentage of 'Fancy + Choice' kernels than did the NPC treatment. The difference is likely the result of the much greater in-shell cropload of the NPC treatment over that of the three pruned treatments.

There were no treatment effects on percentage kernel or grade for nut meats produced during the second production season (2004) when all four treatments exhibited an OFF crop year in regard to in-shell yields (Table 2). With the return of an ON crop year in 2005, all three pruning treatments again substantially increased percentage kernel and percentage of 'Fancy + Choice' meats over the NPC strategy. This increase in quality was substantial and similar to that of the 2003 crop season. The percentage of 'Fancy + Choice' meats was roughly $82 \%$ to $85 \%$ that of the pruned treatments. After the fourth year of pruning, an OFF year, the HD2 treatment exhibited a lower, yet still suitable, kernel percentage and percentage 'Fancy + Choice' than the other treatments. When viewed as an average of all 4 years of the study, nuts produced by the three pruning treatments were equivalent in kernel percentage and were superior to the NPC control treatment. A similarly relationship also occurred regarding percentage of 'Fancy + Choice' meats in that HD and HS pruning treatments improved nut meat quality relative to that of the NPC treatment. By comparison, Lombardini (2006) observed that one-time hedge pruning of 'Desirable' increased kernel percentage and kernel grade in 2 of 3 years over the nonpruned control.

Marketable yield and alternate bearing. Potential gross revenue from orchard enterprises is a function of both in-shell yield and kernel quality characteristics. Integration of these yield parameters results in an assessment of the four pruning strategies in a commercial-like enterprise (Table 3). After the conclusion of the first production season after initiation of the pruning treatments, the absolute weight of marketable nut meats was greatest in the NPC treatment $\left(821 \mathrm{~kg} \cdot \mathrm{ha}^{-1}\right)$ and lowest in the HD and HS treatments ( $70 \%$ to $77 \%$ of the NPC treatment). Marketable yield among treatments did not differ during the second year of the study. By the 
Table 2. Annual percentage kernel and grade quality of nuts produced from 'Desirable' trees receiving one of four mechanical pruning treatment strategies in each of 4 years beginning in 2003. ${ }^{2}$

\begin{tabular}{|c|c|c|c|c|c|c|c|c|c|c|}
\hline \multirow[b]{2}{*}{ Pruning treatment } & \multicolumn{5}{|c|}{ Kernel (\%) } & \multicolumn{5}{|c|}{ Fancy + Choice $(\% \text { total })^{y}$} \\
\hline & 2003 & 2004 & 2005 & 2006 & Avg & 2003 & 2004 & 2005 & 2006 & Avg \\
\hline$\overline{\mathrm{NPC}}$ & $49.2 \mathrm{~b}^{\mathrm{x}}$ & $55.0 \mathrm{a}$ & $47.4 \mathrm{~b}$ & $4.9 \mathrm{a}$ & $51.6 \mathrm{c}$ & $88.2 \mathrm{~b}$ & $95.6 \mathrm{a}$ & $78.1 \mathrm{~b}$ & $97.4 \mathrm{a}$ & $89.8 \mathrm{~b}$ \\
\hline $\mathrm{HD}$ & $53.7 \mathrm{a}$ & $55.2 \mathrm{a}$ & $51.7 \mathrm{a}$ & $54.0 \mathrm{a}$ & $53.6 \mathrm{ab}$ & $96.6 \mathrm{a}$ & $96.0 \mathrm{a}$ & $92.1 \mathrm{a}$ & $95.4 \mathrm{a}$ & $95.0 \mathrm{a}$ \\
\hline HD2 & $50.4 \mathrm{~b}$ & $54.9 \mathrm{a}$ & $53.9 \mathrm{a}$ & $51.6 \mathrm{~b}$ & $52.7 \mathrm{a}$ & $94.8 \mathrm{a}$ & $94.4 \mathrm{a}$ & $92.5 \mathrm{a}$ & $91.0 \mathrm{~b}$ & $93.2 \mathrm{ab}$ \\
\hline
\end{tabular}

${ }^{2}$ Nonpruned control (NPC); annual pruning on two faces in winter (HD); annual pruning on two faces in summer (HS); and biennial pruning on alternate faces in winter (HD2).

${ }^{\mathrm{y}}$ Nut meat grades based on kernel color. Amber color grades and defects were discarded.

${ }^{\mathrm{x}}$ Means within columns followed by different letters are significantly different at $\alpha \leq 0.05$ level by Tukey-Kramer honestly significant difference test.

Table 3. Annual marketable nut meats and associated alternate bearing index (ABI) of 'Desirable' trees receiving one of four mechanical pruning treatment strategies in each of 4 years beginning in $2003{ }^{\mathrm{z}}$

\begin{tabular}{lcccccc}
\hline & \multicolumn{5}{c}{$\begin{array}{c}\text { Annual Fancy }+ \text { Choice } \\
\text { nut meat yield }\left(\mathrm{kg} \cdot \mathrm{ha}^{-1}\right)\end{array}$} & $\begin{array}{c}\text { ABI of marketable } \\
\text { nut meats }(I)^{\mathrm{x}}\end{array}$ \\
\cline { 2 - 6 } Pruning treatment & 2003 & 2004 & 2005 & 2006 & Avg & $0.51 \mathrm{a}$ \\
NPC & $821 \mathrm{a}^{\mathrm{y}}$ & $393 \mathrm{a}$ & $960 \mathrm{a}$ & $124 \mathrm{~b}$ & $574 \mathrm{a}$ & $0.22 \mathrm{~b}$ \\
HD & $635 \mathrm{bc}$ & $305 \mathrm{a}$ & $516 \mathrm{~b}$ & $473 \mathrm{a}$ & $528 \mathrm{ab}$ & $0.19 \mathrm{~b}$ \\
HS & $574 \mathrm{c}$ & $335 \mathrm{a}$ & $418 \mathrm{~b}$ & $280 \mathrm{ab}$ & $442 \mathrm{~b}$ & $0.16 \mathrm{~b}$ \\
HD2 & $709 \mathrm{ab}$ & $426 \mathrm{a}$ & $502 \mathrm{~b}$ & $362 \mathrm{ab}$ & $451 \mathrm{~b}$ & \\
\hline
\end{tabular}

${ }^{\mathrm{z} N o n p r u n e d ~ c o n t r o l ~(N P C) ; ~ a n n u a l ~ p r u n i n g ~ o n ~ t w o ~ f a c e s ~ i n ~ w i n t e r ~(H D) ; ~ a n n u a l ~ p r u n i n g ~ o n ~ t w o ~ f a c e s ~ i n ~}$ summer (HS); and biennial pruning on alternate faces in winter (HD2).

${ }^{y}$ Nut meat grades based on kernel color. Amber color grades and defects were discarded.

${ }^{\mathrm{x}}$ Means within columns followed by different letters are significantly different at $\alpha \leq 0.05$ level by TukeyKramer honestly significant difference test.

Table 4. Light and growth (vegetative and reproductive) characteristics within the interior of 'Desirable' trees mechanically pruned in one of four different ways after 4 years of pruning treatments. ${ }^{\mathrm{z}}$

\begin{tabular}{lcccc}
\hline & & & & \\
PPFD & of exterior \\
Pruning treatment & $\left(\mu \mathrm{mol} \cdot \mathrm{s}^{-1} \cdot \mathrm{m}^{-2}\right)$ & surface light) & Shoots (no.) & Fruit (no.) \\
\hline NPC & $191 \mathrm{ab}^{\mathrm{y}}$ & $10.3 \mathrm{ab}$ & $3.6 \mathrm{~b}$ & $2.5 \mathrm{~b}$ \\
HD & $121 \mathrm{~b}$ & $6.6 \mathrm{~b}$ & $7.0 \mathrm{a}$ & $5.6 \mathrm{a}$ \\
HS & $87 \mathrm{~b}$ & $4.7 \mathrm{~b}$ & $5.1 \mathrm{~b}$ & $5.3 \mathrm{a}$ \\
HD2 & $233 \mathrm{a}$ & $12.6 \mathrm{a}$ & $3.5 \mathrm{~b}$ & $4.1 \mathrm{a}$ \\
\hline
\end{tabular}

zParameters are an average of sampling from three 1.8-m (6 feet) diameter zones (25\%, 50\%, and 75\% of the canopy height) along the central axis of the tree's interior canopy. Light measurements are between 1400 and 1500 solar time. Nonpruned control (NPC); annual pruning on two faces in winter (HD); annual pruning on two faces in summer (HS); and biennial pruning on alternate faces in winter (HD2).

${ }^{\mathrm{y}}$ Means within columns followed by different letters are significantly different at $\alpha \leq 0.05$ level by TukeyKramer honestly significant difference test.

$P P F D=$ photosynthetic photon flux density.

third year of the study, the three pruning strategies were statistically equivalent, producing only $\approx 44 \%$ to $55 \%$ as many marketable meats as the nonpruned control. By the fourth year of pruning, and after continued tree encroachment by the NPC trees, the HD treatment was superior to the NPC treatment in marketable yield, producing approximately fourfold that of the NPC treatment; however, the HD treatment did not differ from that of the other two pruning treatments. Average marketable yield over the 4-year study was statistically equivalent between the NPC and HD treatments, with the HS and HD2 treatments being only $\approx 77 \%$ to $78 \%$ that of the NPC control. Thus, it appears that over the long term, the hedge-pruning strategies used in this study were not as detrimental to marketable yield as might first appear when one considers the amount of canopy removed. This is especially true for the HD strategy in which canopies were hedged on opposite faces each dormant season.
The alternate bearing index of marketable meats was 0.51 for the NPC treatment but only 0.16 to 0.22 for the pruning treatments. Thus, hedge pruning greatly reduced the intensity of alternate bearing over a period of two biennial bearing cycles but did not eliminate alternate bearing. The alternate bearing index of marketable meats was slightly less than that of in-shell nuts. A similar reduction in $I$ was observed for mechanically hedge-pruned 'Wichita' and 'Western Schley' trees growing in a dry and sunny environment (Wood and Stahmann, 2004) and for 'Desirable' trees in relatively humid and cloudy environments (Lombardini, 2006; Worley, 1985).

Internal canopy characteristics. The characteristics of the central internal zone of tree canopies of each of the four pruning strategies was assessed after 4 years of treatment in an attempt to estimate the responsiveness of interior zones of 'Desirable' trees to pruning-induced changes in the light environment. Internal $P P F D$ was very similar in all four strategies but with the HD2 pruning treatment receiving slightly more sunlight than that of the other treatments (Table 4). The internal zones of all treatments were substantially shaded, receiving roughly 87 to $233 \mu \mathrm{mol} \cdot \mathrm{s}^{-1} \cdot \mathrm{m}^{-2}$ during early afternoon. This amount of light energy was $\approx 5 \%$ to $13 \%$ of that received at the canopy's exterior surface (Table 4). The number of shoots present within the interior canopy zone was greatest for the HD treatment with there being no difference among the NPC, HS, and HD2 treatments (Table 4). The number of fruit within the interior canopy zone was very low for all treatments, being equivalent among the three pruning treatments, but only approximately twofold greater than that within the same zone for the NPC treatment (Table 4). The growth of vegetative and reproductive shoots within the internal canopy of mechanically pruned trees was only slightly improved by pruning; however, there was no detectable improvement in internal $P P F D$. The slight increase in number of shoots and number of fruits indicates that this is likely, although the increase in light was insufficient to trigger substantial development of flowering shoots within tree canopies such as is commonly observed in cultivars hedge pruned in relatively high-light regions such as east-central Australia, the southwestern United States, and northern Mexico.

Pecan can produce shoots on scaffold limbs and central leaders of the trunk within the interior zone of canopies. Such shoots arise from either the release of preformed suppressed buds embedded in stem periderm tissue, i.e., adventitious bud, or from suppressed buds (Zimmerman and Brown, 1974). Such buds are released if the associated light environment becomes adequate or on girdling. In the case of 'Desirable' trees of the present study, moderate-width hedge pruning of canopies did not change the light environment enough to stimulate much additional internal shoot growth or fruiting.

\section{Conclusion}

Mechanical hedgerow-type pruning of a crowded 25-year-old 'Desirable' orchard caused a variety of changes in horticultural traits, some positive and some negative. Unfavorable consequences are 1) a $\approx 25 \%$ to $43 \%$ reduction in-shell nut yields; 2) a reduction of $\approx 8 \%$ to $23 \%$ in marketable nut meat yield; and 3) little or no stimulation of shoot development or fruiting within the 
central interior zone of tree canopies. Favorable consequences are 1) increased kernel percentage of nuts; 2) increased grade of nuts; 3) reduced alternate bearing intensity; and 4) reduced orchard crowding. The combination of a likely reduction in marketable yield over a 4-year period, or two alternate bearing cycles, plus the $\$ 150$ to $\$ 300$ U.S. per ha annual cost for mechanical hedge pruning and subsequent orchard floor cleanup, makes it unlikely that any of these pruning strategies will prove attractive within the first 4 years of a hedge pruning-based management program. Summer pruning, relative to dormant season pruning, did not improve long-term marketable yield and did not improve development of fruiting shoots within the interior of trees. Inspection of canopies of pruned trees, regardless of pruning treatment, indicated that $\approx 70 \%$ to $80 \%$ of fruit production occurs within $\approx 1 \mathrm{~m}$ of the canopy surface.

These results indicate that none of the three mechanical moderate-width side-hedge pruning strategies used in this 'Desirable' orchard led to greater average marketable yield than leaving trees in the ever-crowding state. However, eventually nonpruned trees would undoubtedly lose enough canopy as a result of shading to cause substantial diminishment in yield and quality of nuts. It is noteworthy that pruning treatments gave greater year-to-year stability in both in-shell and marketable nut meat yields while reducing intertree competition for sunlight as canopy volumes and diameters diminished because of the hedging treatment. It is likely that, when viewed within a long-term context of greater than 4 years, that moderate-width hedge-type pruning treatments might even- tually prove superior to nonpruned trees as tree crowding gradually reduces canopy volume over the years. Results indicate that mechanized hedgerow-type canopy pruning likely has little potential for increasing shortterm orchard revenue in 'Desirable' orchards that are just beginning to crowd when located in a relatively low-light subtropical climatic group zone, yet long-term potential value appears likely as orchard crowding becomes more severe over time. Further assessment of the long-term value of hedging 'Desirable' trees in crowded orchards awaits comparison against other strategies such as orchard thinning through tree removal or against different canopy pruning strategies based on less frequent (i.e., 3- or 4-year cycles) "side-hedge pruning" or "side-pruning plus topping" cuts. Results from this study support the notion that pecan cultivars being cultivated under relatively low-light conditions do not respond well to moderate-width hedge-type pruning, because they fail to stimulate substantial development of fruiting wood within the interior of canopies or along scaffold limbs. The region's $\approx 22 \%$ to $33 \%$ deficiency in the absolute amount of possible sunlight (received during the growing season) relative to high-light pecan growing regions where mechanical hedge-type pruning has proven efficacious appears sufficient to prevent proliferation of fruiting shoots within the interior of canopies as a consequence of pruning. Although mechanical hedge-type pruning may yet prove efficacious in relatively lowlight subtropical group climatic zones such as the southeastern United States, moderatewidth canopy short-cycle pruning strategies do not appear efficacious for 'Desirable' when viewed over the short term. It therefore seems that wide-width canopy side-hedging strategies, with cuts made on a 3- to 4-year cycle, merit evaluation as a commercial alternative to the mechanical hedge-pruning strategies evaluate in the present study.

\section{Literature Cited}

Conner, P.J. and R.E. Worley. 2000. Alternate bearing intensity of pecan cultivars. HortScience 35:1067-1069.

Finn, G.A., A.E. Straszewski, and V. Peterson. 2007. A general stage key for describing trees and woody plants. Ann. Appl. Biol. 151:127131.

Hudson, W., J. Brock, S. Culpepper, W. Mitchem, and L. Wells. 2007. Georgia pecan pest management guide. Georgia Coop. Ext. Serv. Bulletin No. 841

Jacobs, W.C. 1968. Climatic Atlas of the U.S. U.S. Dept. of Commerce, Washington, DC.

Lombardini, L. 2006. One-time pruning of pecan trees induced limited and short-term benefits in canopy light penetration, yield, and nut quality. HortScience 41:1469-1473.

Pearce, S.C. and S. Dobersek-Urbanc. 1967. The management of irregularity in growth and cropping. J. Hort. Sci. 42:295-305.

Trewartha, G.T. 1968. An introduction to climate. McGraw-Hill, New York, NY.

Wood, B.W., J.A. Payne, and O. Jones. 1990. Transplanting bearing pecan trees. HortScience 35:916-918

Wood, B.W. and D. Stahmann. 2004. Hedge pruning pecan. HortTechnology 14:63-72.

Worley, R.E. 1985. Effects of hedging and selective limb pruning of Elliott, Desirable, and Farley pecan trees under three irrigation regimes. J. Amer. Soc. Hort. Sci. 110:12-16.

Zimmerman, M.H. and C.L. Brown. 1974. Trees: Structure and function. Springer-Verlag, New York, NY. 